\title{
NARRATIVA E RESISTÊNCIA: CONTO BRASILEIRO CONTEMPORÂNEO
}

\section{Luana Porto 1}

Resumo: Este artigo aborda como a perspectiva de resistência se manifesta no conto brasileiro contemporâneo, buscando identificar na forma e no tema de contos brasileiros do século XXI meios de resistência a qualquer situação de caráter conflitivo, não circunscrevendo a abordagem de resistência na literatura a episódios históricos específicos que poderiam gerar um teor testemunhal ou uma memória de fatos sociais representados nos contos. Para isso, expõe-se a concepção de resistência de Alfredo Bosi e análise de narrativas publicadas a partir dos anos 2000: "Boi", de Marçal Aquino, e "O sorriso de brinquedo", de Carlos Gildemar Pontes.

Palavras-chave: resistência; conto brasileiro contemporâneo; forma narrativa.

\begin{abstract}
This article approaches how the perspective of resistance is manifested in the contemporary Brazilian tale, seeking to identify in the form and theme of Brazilian short stories of the 21st century means of resistance to any situation of conflicting character, not circumscribing the approach of resistance in the literature to specific historical episodes that could generate a testimonial content or a memory of social facts represented in the stories. For this, the conception of resistance of Alfredo Bosi and analysis of published narratives from the years 2000: "Boi", by Marçal Aquino, and " O sorriso de brinquedo", by Carlos Gildemar Bridges is exposed.

Key-words: resistance; contemporary Brazilian tale; narrative form.
\end{abstract}

\section{Considerações preliminares}

No contexto dos estudos literários, "resistência" tem sido uma expressão com conotação teórico-crítica frequentemente referida para tratar de obras que problematizam episódios históricos de exceção, como as Ditaduras Militares vivenciadas na América Latina e tematizadas tanto em prosa quanto em verso por diferentes autores, ou momentos do chamado pós-colonialismo, no caso de literaturas produzidas em países tornados independentes politicamente, como é possível verificar em grande parte de literaturas africanas de expressão portuguesa. Dizer que uma obra literária está associada a uma perspectiva de resistência implica, nessa linha de raciocínio, apontar elementos de ordem temática ou temática e formal que atestam a contrariedade do texto artístico a um sistema social, a um regime político, a uma experiência cultural, a determinadas práticas sociais, como as relacionadas a gênero, identidade, violência, marginalização etc. Resistir através da literatura, portanto, é uma forma de "lutar" contra algum sistema ou situação, de combater ideais, de reagir a perseguições ou

\footnotetext{
${ }^{1}$ Doutora em Letras - Literatura Comparada pela Universidade Federal do Rio Grande do Sul e Professora do Programa de Pós-graduação em Letras - Mestrado em Letras e do curso de Letras da Universidade Regional Integrada, câmpus de Frederico Westphalen, Rio Grande do Sul.
} 
imposições de modelos de comportamento socialmente legitimados. Para exemplificar essa afirmação, cito dois trabalhos que exploram a ideia de resistência da literatura.

O primeiro, "Resistência e Crítica: Revistas Culturais Brasileiras nos tempos da Ditadura", de Maria Lucia de Barros Camargo, publicado em dois periódicos e em dois momentos diferentes ${ }^{2}$, discute o espaço da literatura e outras artes, como cinema e música, em revistas culturais publicadas no Brasil nos anos de chumbo. Citando especialmente o caso da Revista Civilização Brasileira, que foi lançada em março de 1965 e é apontada como um "marco inaugural da resistência ao golpe militar exercida nas e pelas revistas culturais" (2010, p. 6), já que criou espaço para vozes intelectuais e artísticas avaliarem o movimento ditatorial, a autora defende ser a resistência um traço da literatura produzida no Brasil durante a Ditadura Militar. Nas palavras de Camargo, "A resistência tem sido uma das principais chaves explicativas para se tratar da literatura e da cultura no Brasil durante a ditadura militar" (2010, p. 5).

Artistas e intelectuais, por meio de seus textos, estabeleciam resistência cultural ao combater o regime militar, criando-se um cenário de oposição entre progressistas e conservadores, libertários e repressores, esquerda e direita, e "não resistir significava aderir; não ser 'progressista', ou 'de esquerda', significava ser 'conservador', ou 'de direita'." (2010, p. 5). Nesse contexto, a obra de resistência é valorizada entre a população mais escolarizada e politizada e "a resistência irá caracterizar, fomentar e distinguir a produção cultural, cujos produtos passam a desfrutar de um público crescente" (2010, p. 5), que passa a ter revistas e imprensa alternativa dedicadas à publicação de textos de resistência, seja na forma de ensaio, literatura ou música.

A segunda perspectiva de resistência é exemplificada pelo estudo de Silvio Ruiz Paradiso (2012), que propõe uma relação entre resistência e processo de colonização na literatura angolana produzida pós-independência do país, especialmente em textos do escritor Viriato da Cruz, autor privilegiado no estudo. Para Paradiso, o movimento de descolonização radical e violento vivenciado no país africano "criou uma estética literária mais agressiva e crítica" (2012, p. 197), que caracteriza uma forma de resistência no sentido de que obras literárias criticam valores colonialistas impostos a comunidades africanas e questionam a subserviência do colonizado diante do colonizador. No caso específico do escritor Viriato da Cruz, há, na leitura proposta por Paradiso para o poema "O Makèzú", a exposição da diferença cultural, materializada na abordagem da experiência histórica do ponto de vista do colonizado e não do colonizador, que tende a objetificar o colonizado, sua cultura e vivência

${ }^{2} \mathrm{O}$ artigo "' foi publicado inicialmente na Revista Iberoamericana, em 2004, e mais tarde no Boletim de Pesquisa NELIC, da UFSC, em 2010. 
nativa. Essa visão da diferença configura uma forma de resistência, já que "Expor a diferença sob o ponto de vista do escritor africano é resistir e revidar o discurso imperial, migrando-o da margem ao centro do discurso literário." (2012, p. 199).

Os trabalhos de Camargo (2010) e Paradiso (2012) apresentam dois traços em comum em relação à visão sobre literatura de resistência que podem ser percebidos em outros estudos sobre o tema. Ambas leituras e perspectivas de identificação da resistência na literatura estão amparadas na ideia de resistência como uma forma de criação "datada", marcada por uma temporalidade específica, por uma temática singular, identificada pela problematização de um momento histórico determinado, como Ditadura, Guerra, colonização, ou por ações decorrentes de um episódio específico. Isso levame a supor, acompanhando essa linha de raciocínio, que a resistência não teria lugar na literatura se não houvesse conflito decorrente de episódio histórico para ser tratado no texto literário. Essa percepção, como procurarei mostrar neste texto, não parece ser adequada para pensar textos da literatura brasileira contemporânea.

O outro traço que une as duas perspectivas críticas diz respeito ao fato de associarem predominantemente ideia de resistência a uma abordagem temática no processo de interpretação literária, seja em texto que aborda a Ditadura Militar, no estudo de Camargo, seja texto que trata do período pós-colonial, no trabalho de Paradiso, o que sugere uma tendência de supremacia de elementos conteudísticos em detrimento dos elementos formais na análise literária. Dessa forma, categorias fundamentais que distinguem o texto artístico de um texto não artístico, como a linguagem, a configuração a voz que fala, a forma e o gênero, seriam relegadas a um segundo plano ou ignoradas, fazendo com que o texto literário seja mais reconhecido por sua "potencialidade argumentativa" do que por sua "elaboração estética".

Tais ponderações acerca da exploração da perspectiva de resistência na literatura levam-me a pensar como essa concepção pode ser tratada/discutida na literatura brasileira, mais especificamente no conto contemporâneo do século XXI, cujas produções, em sua maioria, têm se pautado não na ficcionalização de eventos históricos específicos, mas sim na exposição de conflitos que são inerentes ao comportamento humano, a contextos de exclusão e a uma sociedade, como a nossa, fundada em 
experiências de violência a qual é parte constitutiva de nossa cultura como já apontaram Karl Erik Scholhammer (2000) $)^{3}$, Tânia Pellegrini (2005) ${ }^{4}$.

Como proponho uma reflexão sobre a literatura brasileira no século XXI, convém registrar que, dentre os traços apontados pela crítica literária corrente para caracterizar a narrativa literária deste período, estão o registro de cenas do cotidiano, a violência como tema recorrente, o fazer literário articulado ao suporte tecnológico, a emergência de escrita proveniente de espaços periféricos, a presença de novos suportes de divulgação dos textos e o desenvolvimento de uma consciência artística entre os autores. Esta consciência acerca do processo de produção literária, para Helena Bonito Pereira, tem se intensificado cada vez mais, "levando-os a buscar obstinadamente novas formas de reflexão sobre a linguagem, o texto, a ficção, em inesgotáveis exercícios metalinguísticos e intertextuais." (PEREIRA, 2011, p. 43). Além disso, essa produção é caracterizada pela multiplicidade, apontada por Beatriz Resende como "fator muito positivo, original, reativo diante das forças homogeneizadoras da globalização.” (RESENDE, 2008, p. 20). Enfim, há vários apontamentos que asseveram a multiplicidade de traços da literatura contemporânea publicada no Brasil deste século. Em nenhum dos estudos citados, os quais são referências bastante exploradas em pesquisas sobre literatura brasileira contemporânea, a ideia de resistência é apontada como algo a singularizar os textos desse período.

Embora a aproximação da concepção de resistência para a discussão sobre o conto brasileiro do século XXI não seja uma coordenada da crítica literária sobre a narrativa curta deste período, entendo que ser um caminho interessante para compreender o conto em sua forma e conteúdo, numa leitura que conjuga literatura e vida social.ao caracterizar a literatura brasileira do século XXI. Dessa forma, proponho uma questão central, que norteará as seções seguintes deste texto: Como a resistência se manifesta no conto brasileiro contemporâneo? Ao tentar responder a esse questionamento, busco identificar na forma e no tema de contos brasileiros do século XXI meios de resistência a qualquer situação de caráter conflitivo, não circunscrevendo a abordagem de resistência na literatura a episódios históricos específicos que poderiam gerar um teor testemunhal ou uma memória de fatos sociais

\footnotetext{
${ }^{3}$ Para o autor, a violência é uma marca fundadora da cultura brasileira, e o tema da violência é recorrente na literatura moderna do Brasil, o que não permite compreender a presença intensa dessa temática como uma "extravagância de gosto duvidoso ou aberração" (2000, p. 236).

4 Segundo a pesquisadora, a violência é uma prática constitutiva da cultura brasileira e que as obras artísticas, independentemente de sua natureza, abordam a violência "como um elemento fundador a partir do qual se organiza a própria ordem social e, como consequência, a experiência criativa e a expressão simbólica, aliás, como acontece com a maior parte das culturas de extração colonial" (p. 134). Dessa forma, a autora explica que, ao longo da história literária brasileira, a violência foi explorada através de diferentes matizes tanto na prosa quanto na poesia e esteve relacionada a diversos temas, como a conquista do Brasil, a ocupação da terra brasileira pelos portugueses, a colonização, o aniquilamento dos índios, a escravidão, as lutas pela independência, a formação das cidades e dos latifúndios, os processos de industrialização, o imperialismo, as ditaduras, entre outros.
} 
representados nos contos. Isso não implica desconsiderar a percepção de que dados da realidade externa são incorporados à obra, tornando-se constituintes da forma estética dos textos, tal como propõe Antonio Candido (1996). Para isso, exponho a concepção de resistência de Alfredo Bosi e na sequência, examino de modo especial narrativas publicadas a partir dos anos 2000: "Boi”, de Marçal Aquino, e "O sorriso de brinquedo", de Carlos Gildemar Pontes.

\section{O conceito de resistência na proposição de Alfredo Bosi}

O livro Literatura e resistência, lançado em 2002, assim momo o ensaio "Narrativa e resistência", de 1996, antes de se constituírem uma proposição teórica sobre o processo de escrita literária, são o registro de um posicionamento político de seu autor. Alfredo Bosi marca sua postura de rejeição ao conservadorismo e a práticas de autoritarismo, mostrando que conflitos sociais ou forças externas não podem ser dissociados da compreensão da composição literária e dos problemas de estrutura e forma textual. Contudo, isso não significa compreender a obra apenas por elementos do contexto de produção e sim compreender de que forma dá a articulação entre escolhas estéticas e conteúdo social, o que aproxima a perspectiva de Bosi a de teóricos da Escola de Frankfurt, como Theodor Adorno.

Para Alfredo Bosi, a resistência é concebida prioritariamente no campo ético e não no estético. Nas palavras do autor, "Resistência é um conceito originariamente ético, e não estético.” (1996, p. 11), e a força própria resiste à força alheia num movimento de criação que toma a intuição como elemento posterior da razão, já que o escritor não cria por força de vontade. Mesmo alertando para não haver confusão entre conceitos da arte e conceitos de ética e política, Bosi (1996) reconhece que se amarram “as pulsões e os signos, os desejos e as imagens, os projetos políticos e as teorias, as ações e os conceitos" e que essa interação é "garantia da vitalidade mesma das esferas artística e teórica" (1996, p. 13).

Ao propor a associação entre "narrativa" e "resistência", seguindo uma lógica esboçada nos anos 1970 para a operacionalização do termo "poesia de resistência", Bosi expõe duas formas, não excludentes, de verificação da resistência no texto narrativo: a resistência materializada como tema e a resistência realizada no processo de escrita. No momento de "translação" da ética para a estética, no texto em prosa, o narrador explora seus valores em contraposição aos antivalores, os quais podem ser exemplificados pela oposição entre igualdade e iniquidade, sinceridade e hipocrisia, e, como o escritor de prosa dispõe de uma "liberdade inventiva”, “ O narrador cria, segundo o seu desejo, representações 
do bem, representações do mal ou representações ambivalentes" (1996, p. 15, grifo do original). Nessa perspectiva, o que mais importa não são os valores defendidos ou abordados, mas a forma como são registrados. Segundo Bosi, "Não são os valores em si que distinguem um narrador resistente e um militante da mesma ideologia. São os modos próprios de realizar esses valores.” (1996, p. 16)

Essa visão de que o que singulariza um narrador resistente é como ele trata ou problematiza os valores é particularmente interessante quando pensamos numa suposta cobrança de que todo escritor deve ser "correto" do ponto de vista político. Para Bosi (1996), é preciso assegurar uma independência entre ponto de vista pessoal do escritor e julgamento ideológico da obra, além de ser necessário distinguir um narrador resistente de um militante da mesma ideologia. Para ele, é arriscado exercer um patrulhamento ideológico sobre o escritor:

O primeiro risco ocorre quando se exige que o escritor se engaje, ao compor sua obra, na propaganda de movimentos sociais ou de campanhas políticas que pretendem realizar determinados valores ou combater os seus respectivos antivalores. (1996, p. 16)

O segundo risco manifesta-se "quando leitores ultra ideologizantes condenam antivalores supostamente representados ou promovidos pelas imagens do poema.” (1996, p. 17). Seria, por exemplo, o caso de um leitor não aceitar ler/interpretar um texto que faz uma representação da violência contra a mulher por rechaçar esse tipo de agressão de gênero, como podemos verificar no miniconto "Cicatriz", de Flora Medeiros.

Ao diferenciar os dois tipos de resistência, como tema e como processo de escrita, Bosi (1996) explica que a primeira (resistência como tema) é verificada diante da abordagem literária de um acontecimento datado, marcado espacial e historicamente ou de situações de exceção que ferem direitos fundamentais, enquanto a segunda (resistência como forma) se relaciona à problematização de modelos de realidade através da experimentação de formas narrativas não convencionais como meio para resistir a valores e antivalores culturalmente impostos ou enraizados. Recursos estéticos para a explicitação da resistência como forma são evidenciados tanto na caracterização da postura do narrador quanto na configuração dos personagens, que podem revelar tensões sociais que são incorporadas na composição literária.

Retomando a pergunta norteadora deste trabalho (Como a resistência se manifesta no conto brasileiro contemporâneo?), passo à análise de dois textos, ambos publicadas no século XXI e que, a meu ver, podem ser lidas como narrativas de resistência, pelo tema e pela forma, tendo-se em vista a dupla acepção para o termo proposta por Bosi (1996). A ideia, ao analisar dois contos, não é a de estender impressões ou julgamentos de valor ao conjunto da literatura brasileira, o que induziria a uma 
generalização interpretativa que o corpus deste trabalho não autoriza apresentar, mas a de apontar que o conceito de resistência pode ser explorado como meio de análise formal e temática do conto do século XXI.

\section{Resistência no conto brasileiro contemporâneo: uma leitura de "Boi e "O sorriso de brinquedo"}

O conto "Boi", de Marçal Aquino, integra o livro Famílias terrivelmente felizes, publicado em 2003 e composto de 21 textos. A narrativa é ambientada em um cenário de marginalidade social em que vivem dois moradores de rua (Boi e Eraldo) que disputam um barraco na beira de um viaduto em um grande centro urbano. Os dois personagens vivem em constante tensão por nunca saberem se terão um barraco para onde voltar à noite e porque, assim que o dia amanhece, têm de deixar suas moradas para dar lugar à movimentação diária de um espaço citadino rodeado de repartições onde circulam muitas pessoas ao longo do dia e para as quais os dois são invisíveis. Nesse contexto de moradia precária, ainda há o agravante da falta de comida e do conflito/disputa entre os dois para decidir com quem fica o "lar", inicialmente de posse de Eraldo, já que os dois não aceitam dividir o mesmo casebre, visto por Boi como "o melhor barraco das redondezas" (AQUINO, 2003, p. 182), o que o motiva instituir uma disputa para ficar com o lar dividido em cômodos.

Essa disputa gera o ponto de maior tensão na narrativa, pois envolve luta física, desgaste emocional e violência nas ações. Boi promete dar como pagamento do barraco um revólver a Eraldo, que não aceita por estar bem sozinho no casebre e por este não ser uma "pensão". Boi vai então no dia seguinte com dois capangas e tenta expulsar Eraldo do barrado, mas é surpreendido pela oferta que Eraldo faz aos dois homens, que é oferecer dinheiro para bater em Boi sem dó: "Estou pagando pela surra. Que é pra ele aprender" (2003, p. 185). Boi acaba conseguindo se desvencilhar dos dois capangas e, de posse do revólver, vai mais uma vez ao barraco. Lá entra em luta corporal com Eraldo, que escorrega, rola pela encosta e bate a cabeça em uma pedra, fica imóvel, como morto. Boi sente-se o dono do barraco, do qual toma "posse". Mas sua alegria é efêmera, pois no amanhecer é lhe solicitada 
a saída do lugar porque nele será instalado um andaime para construção de estrutura de mobilidade urbana.

A narrativa encerra-se com o encontro, pelos trabalhadores, de um corpo, o de Boi, morto por Eraldo, que, fazendo-se até então de morto, aproveita o momento em que Boi retorna ao interior do barraco para pegar seus últimos pertences antes da saída final e desfere o último tiro, matando Boi. Eraldo, ferido pelo tombo do dia anterior, é conduzido ao hospital, e, como sequela da batida na cabeça, passa a viver em cadeira de rodas num asilo, onde, com dificuldades de fala, só consegue pronunciar o dia inteiro a palavra "Boi", entendida pelos outros velhos do lugar como um meio para ser chamado. Dessa forma, todos o reconhecem como Boi e assim o narrador profecia: "De certa maneira, Boi também sobreviveu". (AQUINO, 2003, p. 191).

Todo o embate é contado do ponto de vista de um narrador que se coloca na posição de observador ora próximo do que narra, ora mais distante, o que cria uma atmosfera de proximidade entre narrador e leitor a qual é ampliada à medida que o texto se constrói seguindo a lógica de um enredo clássico no sentido de contextualização de personagem, desdobramento de enredo, apresentação de desfecho das ações. O narrador em terceira pessoa é onisciente e demostra uma empatia por Boi, já que todo o seu olhar é direcionado para a percepção deste personagem sobre como vive e que faz para atingir seus objetivos, dentre os quais o mais importante é ter onde morar e, para isso, tomar, de alguma forma o barraco de tapume do vizinho Eraldo. A mobilidade do narrador é um elemento de ordem formal que acentua, no processo de escrita do conto, um olha mais humanizado e sensível a um conflito específico de dois homens que podem ser compreendidos como conflitos de ordem coletiva não resolvidos: a dificuldade de sobrevivência de sujeitos marginalizados no contexto cruel das periferias de grandes cidades. O final melancólico do texto e a ideia metafórica da sobrevivência de Boi, aliados à descrição da fragilidade dos personagens, tanto emotiva quanto fisicamente, são indícios de uma tensão social cíclica que se perpetua e não se extingue, o que permite reconhecer a impossibilidade de o conto apontar um caminho de superação da situação-problema que é o mote da narrativa. Essa perspectiva se amplia quando consideramos a dedicatória da narrativa, iniciada com uma indicação de ser o texto uma "Homenagem a João Antonio [1937-1996], poeta dos escombros do mundo" (AQUINO, 2003, p. 180).

Apesar de o conto "Boi" não fazer alusão a um acontecimento histórico específico que mais facilmente poderia atestar o caráter de resistência pelo tema na acepção de Bosi (1996), parece-me possível reconhecer nesta narrativa uma abordagem de uma situação que denuncia/contraria/rechaça a não garantia de vários direitos fundamentais, dentre os quais a dignidade dos sujeitos e o acesso à 
moradia adequada num contexto pós-ditadura militar. Nessa proposta de leitura, a representação de um contexto cruel de sobrevivência é motivação para o reconhecimento de uma resistência enquanto tema, o que pode ser verificado em outros contos da literatura brasileira do século XXI, e que neste caso específico ganha maior intensidade pela caracterização do personagem principal: Boi é assim chamado como meio de aludir à animalização da vida e à brutalidade do homem, sua definição como sujeito em processo de degradação física e moral também contribuem para essa perspectiva de resistência à aceitação de um cenário de miséria humana e social.

O conto "O sorriso de brinquedo", de Carlos Gildemar Pontes, integra a coletânea Contos cruéis: As narrativas mais violentas da literatura brasileira contemporânea, organizada por Rinaldo de Fernandes e publicada em 2006. A narrativa de Pontes gira em torno da disputa de objetos descartados em um lixão por dois mendigos que assaltam depósito de um grande lixão de uma cidade não identificada no conto. Já no viaduto, alegres por terem enchido suas sacolas com os objetos roubados, os dois homens passam a fazer a partilha, e então entram em conflito por uma boneca e a luta se generaliza, resultando em ações de violência e agressividade física:

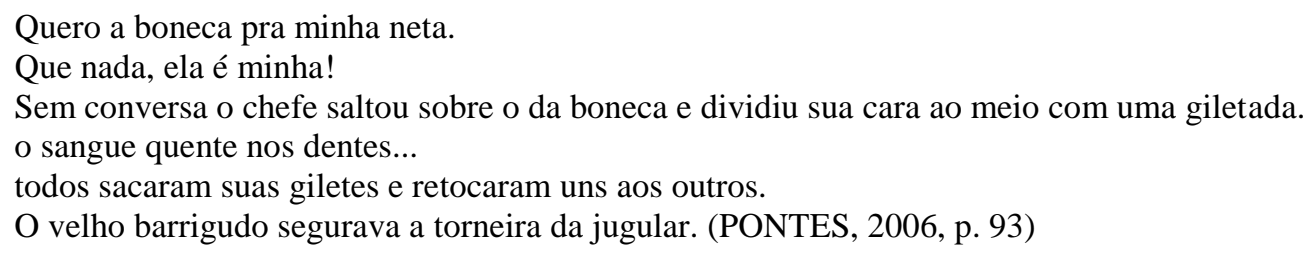

No momento em que os mendigos alimentam o embate, surge uma menina, neta de um deles, e ela aproveita para "tomar a boneca e correr, os cabelos espetando o vento, um olho aberto e outro fechado, o sorriso de brinquedo" (2006, p. 93). Esse fragmento da narrativa é particularmente interessante para a caracterização da menina e/ou da boneca, já que a descrição dos olhos e do sorriso é ambígua, podendo remeter tanto à criança quanto ao brinquedo. De qualquer forma, é através de um objeto que se desencadeia uma situação de satisfação pessoal no meio de tantas fragilidades e condições de vida adversas. Esse traço ambíguo é retomado no final do conto, quando o narrador encerra de forma aberta o texto, dando possibilidades de o leitor supor ou propor uma continuidade narrativa a partir dos planos que podem ser pensados para a menina pelo sujeito que a observa:

Sãs e salvas, as duas moram no sinal.

A boneca, olho fechado, olho aberto, mão estendida recebe as moedas.

O sujeito do outro lado da rua tem planos para a menina. (PONTES, 2006, p. 93) 
A narrativa de "O sorriso de brinquedo" é escrita em meia página, o narrador é observador e distante do que conta, há uma mistura de técnica de composição, que permite reconhecer elemento de conto, miniconto e roteiro cinematográfico no processo de escrita. Além disso, entendo que o conto pode ser lido como uma narrativa de resistência pelo processo de escrita, no sentido de que há vários elementos que contribuem para uma resistência como forma e que estão associados a questões pautadas em meios de representação da experiência: a) a postura do narrador, cuja linguagem objetiva, direta e fria no relato dos fatos acentua uma perspectiva de criar choque de leitura; b) a caracterização generalista dos personagens, não nomeados, sem uma identidade precisa, remetendo à coletividade de sujeitos à margem de processos sociais; c) um tom plural ou híbrido de escrita narrativa, materializado no estilo de conto somado a uma escrita próxima do roteiro cinematográfico e também do miniconto, haja vista a concisão narrativa deste conto e a densidade do que é relatado; d) uma dificuldade de acomodação do conto segundo as teorias do gênero (teorias de Julio Cortazar, Luis Barrerra Linares, Gustavo Luis Carrera e Ricardo Piglia). Essa configuração de personagens e a forma narrativa do conto podem ser compreendidos como dados estéticos que revelam tensões sociais que são incorporadas na composição literária e que externalizam valores e antivalores, do certo e do errado, do justo e do injusto, do bem e do mal etc quando consideramos a sequência de ações que forma o enredo. Isso levame a reconhecer a resistência pela forma como um dado que singulariza o conto analisado.

\section{Considerações finais}

Com uma escrita objetiva, frases curtas, poucos diálogos, vocabulário simples, as duas narrativas podem ser compreendias como exemplos de uma literatura preocupada em construir representações individuais e sociais que (re)modelam a experiência através da escrita e do tema. A forma dos textos indicar ser o trabalho estético atividade de dedicação de seus escritores, o que afasta os contos de uma abordagem superficial da escrita literária e indica uma relação intrínseca entre a forma de contar e a matéria da contação. Essa proximidade de forma e conteúdo permite reconhecer nos textos uma perspectiva de não contemplação aos eventos conflitos que abordagem e uma postura de criação voltada à criação de mecanismos linguísticos e formais para impactar o leitor e desacomodálo de uma visão passiva da própria formação da sociedade brasileira e das formas de interação social.

A busca por uma desacomodação do horizonte de leitura do leitor pode ser compreendida como uma ética contrária à violência e opressão, capaz de sinalizar, via construção literária, o desgaste de 
uma sociedade que precisa reformular seus valores e resistir a diferentes e incessantes meios de opressão ao sujeito em situação de marginalidade. E mais, esse posicionamento ético aponta um outro dado: o inconformismo dos textos (e por que não falar dos criadores?) com as matérias que subsidiam os relatos. Resistir configura-se também como registrar, no processo criativo, a contrariedade ao sistema social vigente no país.

Chamo, por fim, atenção para o fato de que os dois textos problematizam diferentes situações de "sobrevida" e resistência, agora no sentido físico, de personagens que representam grupo silenciados e invisibilizados no plano social. E, apesar de a concepção de resistência ser interessante para a análise de contos do século XXI, seria apressado afirmar que ela se configura uma tendência de escrita da narrativa curta neste indício de século. Para tal afirmação, uma análise de um corpus mais extenso seria necessária, o que não foi a proposta deste ensaio, mas se mostra relevante para identificar o que mais o conto brasileiro do século XXI tem a mostrar sobre a resistência.

\section{Referências}

AQUINO, Marçal. Boi. In: AQUINO, Marçal. Famílias terrivelmente felizes. São Paulo: Cosac Naify, 2003. p. 181-194.

BOSI, Alfredo. Literatura e resistência. São Paulo: Companhia das Letras, 2002.

BOSI, Alfredo. Narrativa e resistência. Itinerários, Araraquara, n. 10, p. 11-27, 1996.

CAMARGO, Maria Lucia de Barros. Resistência e Crítica: Revistas Culturais Brasileiras nos tempos da Ditadura. Boletim de Pesquisa NELIC, v. 10, n. 15, 2010.2, p. 4-33. Disponível em: <https://periodicos.ufsc.br/index.php/nelic/article/view/1984-784X.2010v10n15p05/17874 >. Acesso em: 28 nov. 2016.

CANDIDO, Antonio. Literatura e sociedade. São Paulo: USP/FFLCH/DTLLC, 1996.

PARADISO, Silvio Ruiz. Subserviência e resistência colonial na poesia africana lusófona: uma análise em Viriato da Cruz e Jorge Barbosa. Diálogos \& Saberes, Mandaguari, v. 8, n. 1, p. 195-212, 2012. Disponível em: <http://seer.fafiman.br/index.php/dialogosesaberes/article/viewFile/276/268>. Acesso em: 28 nov. 2016.

PELLEGRINI, Tânia. As vozes da violência na cultura brasileira contemporânea. Crítica marxista, 2005. 2005. Disponível em: <www.unicamp.br/cemarx/criticamarxista/critica21-Apelegirni.pdf>. Acesso em: 18 mar. 2012. 
PEREIRA, Helena Bonito. Breves apontamentos para a história literária brasileira. In: PEREIRA, Helena Bonito. Novas leituras da ficção brasileira no século XXI. São Paulo: Universidade Presbiteriana Mackenzie, 2011. p. 31-47.

RESENDE, Beatriz. A literatura brasileira na era da multiplicidade. In: RESENDE, Beatriz. Contemporâneos: expressões da literatura brasileira no século XXI. Rio de Janeiro: Casa da Palavra: Biblioteca Nacional, 2008. p. 15-40.

PONTES, Carlos Gildemar. O sorriso de brinquedo. In: FERNANDES, Rinaldo (Org.). Contos cruéis: as narrativas mais violentas da literatura brasileira contemporânea. São Paulo: Geração Editorial, 2006. p. 93.

SCHOLHAMMER, Karl Erik. Os cenários urbanos da violência na literatura brasileira. In: PEREIRA, Carlos Alberto M. (org.) Linguagens da violência. Rio de Janeiro: Rocco, 2000. p.236-259.

Recebido em 23 de novembro de 2018 Aceito em 28 de dezembro de 2018 